\title{
DISPOSITIVOS MÓVILES EN LA EDUCACIÓN MÉDICA
}

Resumen:

La gran popularidad y creciente disponibilidad de diversos dispositivos móviles electrónicos ofrece la posibilidad de considerarlos como herramientas para la educación. Los asistentes digitales personales o PDA (acrónimo del inglés Personal Digital Assistants), los reproductores digitales multimedia portátiles y los teléfonos inteligentes (en inglés smartphones) son dispositivos cercanos que pueden emplearse dentro de la enseñanza móvil o mLearning, el aprendizaje que se produce cuando el alumno aprovecha las oportunidades que ofrecen las tecnologías móviles, en cualquier lugar/a cualquier hora. Se exploran las distintas posibilidades que ofrecen estos dispositivos en el campo de la enseñanza de la Medicina.

Palabras clave: computadores de bolsillo; educación médica; aplicaciones de informática médica; reproductor MP3; internet.

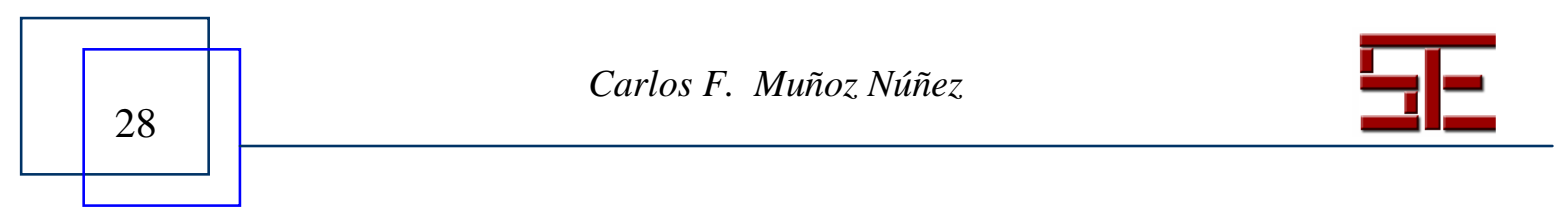




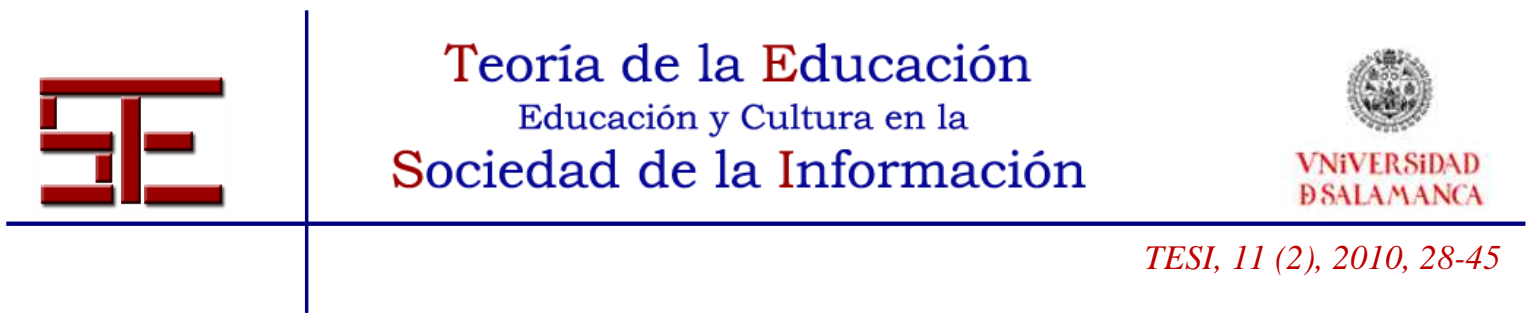

\section{MOBILE DEVICES IN MEDICAL EDUCATION}

Abstract:

The great popularity and growing availability of several mobile devices brings the opportunity of their use as educational tools. PDAs (Personal Digital Assistants), portable multimedia players and smartphones have been are familial devices that can be used for mobile learning (mLearning), learning that happens when the learner takes advantage of the learning opportunities offered by mobile technologies, anywhere/anytime. This work explores the diverse alternatives these devices offer in medical education.

Keywords: computers, handheld; education, medical; medical informatics applications; MP3 player; internet.

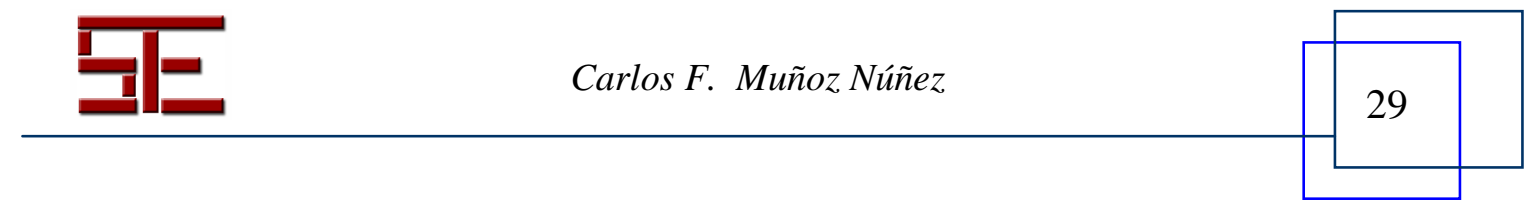




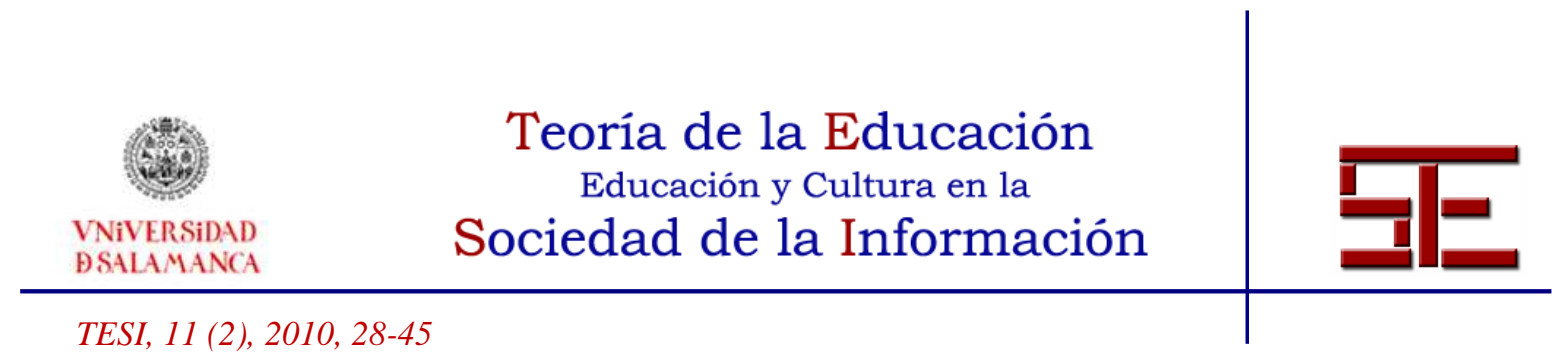

\section{DISPOSITIVOS MÓVILES EN LA EDUCACIÓN MÉDICA}

Fecha de recepción: 15/09/2009; fecha de aceptación: 31/04/2010; fecha de publicación: 05/07/2010

Carlos F. Muñoz Núñez

radiologiaeninternet@gmail.com

Hospital de Torrevieja España

\section{1.- INTRODUCCIÓN}

La progresiva miniaturización de los componentes informáticos ha permitido que los ordenadores tengan cada vez un volumen menor. Los primeros ordenadores ocupaban edificios enteros mientras que en la actualidad es posible llevar dispositivos con potencia de cálculo mucho mayor que aquellos en un bolsillo. Los asistente digitales personales o PDA son pequeños ordenadores de bolsillo con menor potencia y capacidad de almacenamiento que un ordenador de sobremesa que nacieron originalmente como complemento de éste y con funciones de gestores de información personal. Sin embargo tenían además suficiente potencia como para realizar complejos cálculos matemáticos, manejar bases de datos o conectarse a Internet, por citar tan sólo unas pocas de sus funciones. Muchos médicos pronto comenzaron a utilizar estos dispositivos en la práctica diaria como calculadoras médicas, para consultar farmacopeas, para llevar el registro de sus pacientes, para consultar guías de práctica clínica etc. Su tamaño era pequeño, cabían en el bolsillo de la camisa o de la bata y se encendían instantáneamente, eran dispositivos ideales que podían sustituir a la libreta de notas y a los manuales de bolsillo en papel. Muchos estudiantes de Medicina también empezaron a utilizarlos durante las clases para tomar apuntes, leer libros de texto, llevar un registro de prácticas clínicas, etc.

Los reproductores multimedia digitales portátiles son otros pequeños dispositivos móviles que son capaces de reproducir diversas variedades de archivos digitales, como archivos MP3 y MP4. Esta capacidad es la que se aprovecha para reproducir podcasts, unos pequeños archivos de vídeo o que combinan audio y vídeo y que se pueden descargar de Internet gratuitamente previa suscripción. El contenido de los podcasts es

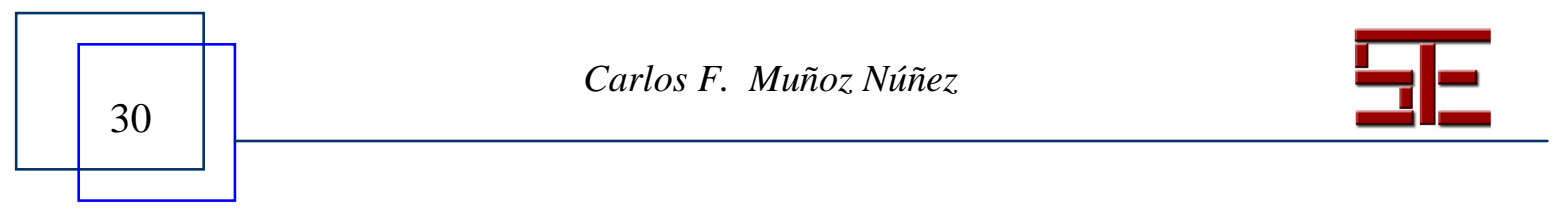




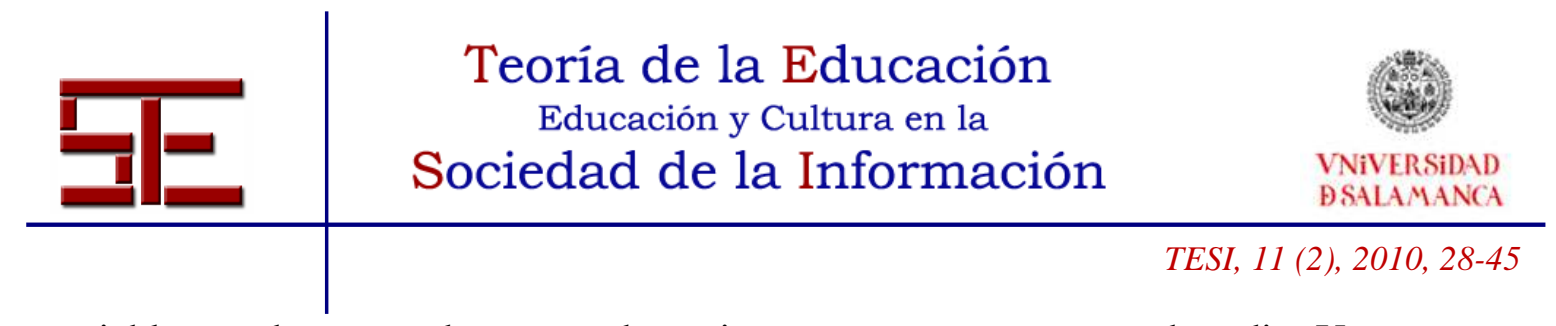

variable, pueden tratar de recetas de cocina o contener programas de radio. Una enorme utilidad de los podcasts es la difusión de conocimiento, al poder contener cualquier tipo de información en forma de sonido con o sin imagen pueden utilizarse para difundir contenido educativo, y en este territorio la Medicina no es ajena, ya hay experiencias de diseminación de podcasts con contenido médico vía Internet tanto para estudiantes de Medicina como para profesionales médicos. Los reproductores multimedia digitales van a permitir la reproducción de ese contenido en el lugar y el momento que deseemos favoreciendo el mLearning.

Los smartphones son otro tipo de dispositivos móviles que combinan las funciones de PDA con las de teléfono móvil, y en los últimos modelos también las funciones de reproductores multimedia digitales portátiles. La reciente introducción de estos dispositivos en el mercado ha ido relegando progresivamente la de los PDA.

En el presente trabajo se revisa el papel desempeñado por los asistentes digitales personales (PDA), los reproductores digitales multimedia y los teléfonos inteligentes (smartphones) en la educación médica.

\section{1.- ASISTENTES DIGITALES PERSONALES}

Los asistentes digitales personales son también conocidos como PDA (acrónimo de su denominación inglesa Personal Digital Assistant). En 1996 revolucionaron la informática con la aparición del primer PDA de éxito que fue el modelo Palm Pilot 1000 de US Robotics ${ }^{\circledR}$, y pronto se convirtieron en unos dispositivos muy populares a los que muy pronto se les encontró aplicación en el campo de la Medicina.

Un PDA es un ordenador compacto de pequeño tamaño y bajo peso que cabe en el bolsillo de una camisa, funciona con baterías, y es independiente del ordenador personal (aunque se beneficia de la interacción con él) y funciona sobre la palma de la mano (de ahí que también se denomine en inglés handheld computer o computadora de mano) (figura 1). La interacción del usuario con la PDA se realiza sobre una pantalla táctil empleando un puntero especial denominado stylus. La pantalla táctil puede variar de resolución dependiendo del modelo, siendo la resolución espacial máxima que han llegado a alcanzar de $640 \times 480$ píxeles con una profundidad de color de 65.000 colores (modelo Dell@ Axim x51v).

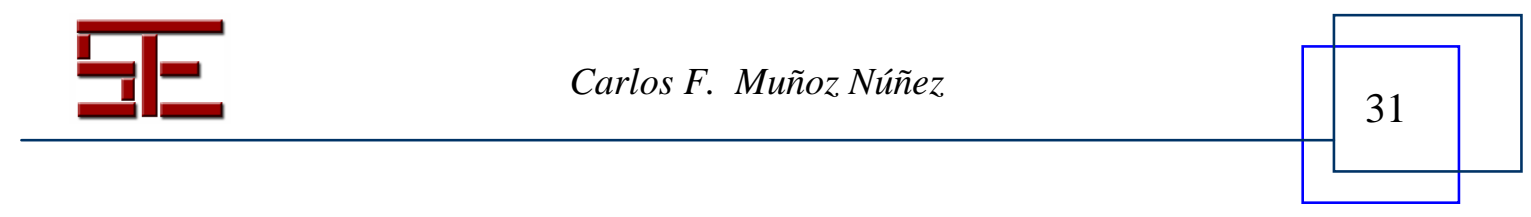




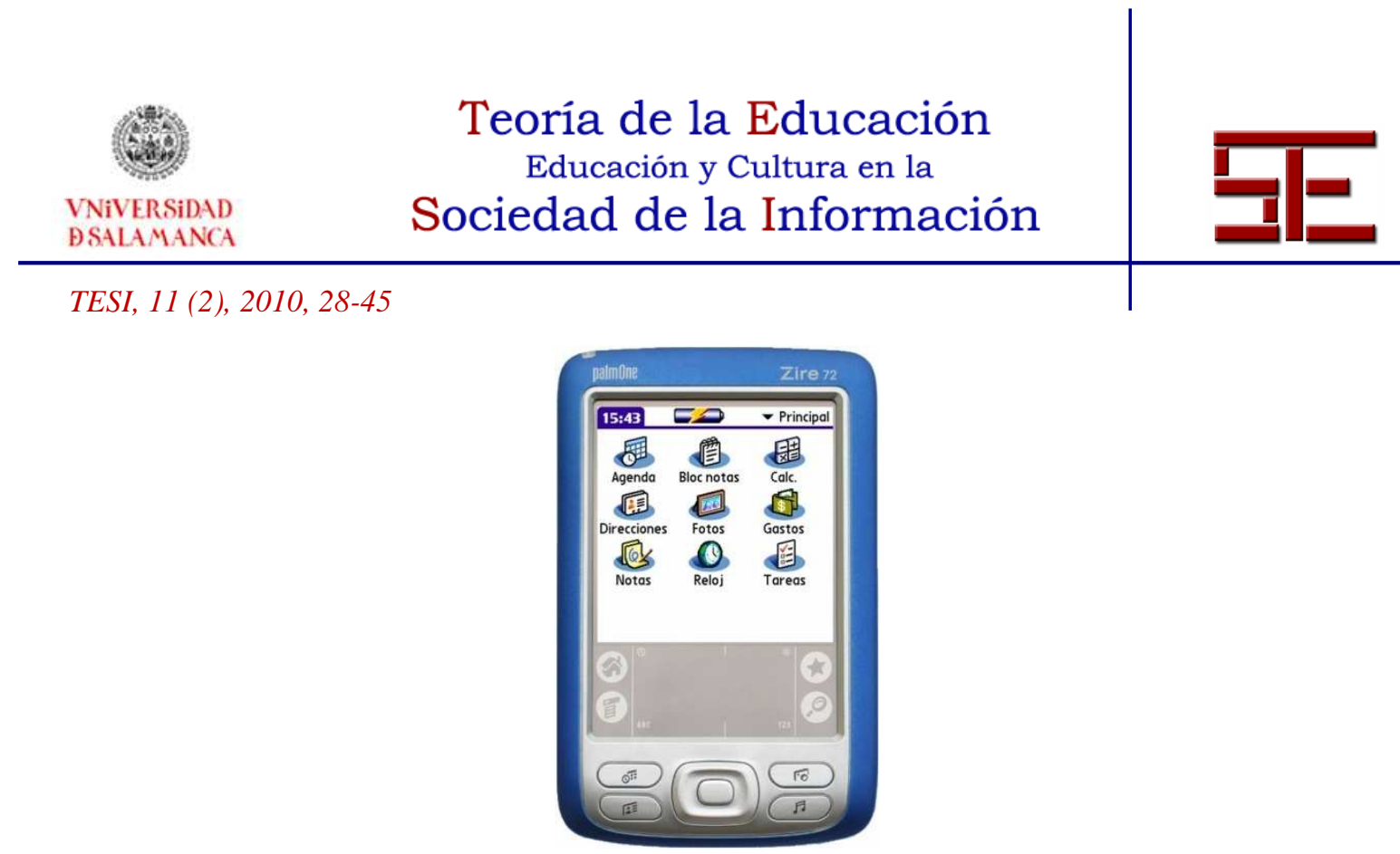

Figura 1; PDA

Existen dos tipos básicos de PDA en función de sus sistemas operativos, los dispositivos Palm bajo sistema operativo PalmOS y los dispositivos PocketPC bajo sistema operativo Windows Mobile.

La entrada de datos en el PDA puede realizarse por varios métodos: (1) a través de un teclado virtual, (2) a través de una técnica de escritura denominada Graffiti, (3) mediante la sincronización con un ordenador personal por puerto USB (acrónimo del inglés Universal Serial Bus) o con tecnología inalámbrica Bluetooth, (4) mediante beaming o transferencia de archivos entre varios PDA utilizando el puerto de infrarrojos del dispositivo o la tecnología Bluetooh o (5) empleando un teclado externo.

La mayoría de PDA suelen disponer de ranuras de expansión para aumentar su capacidad de memoria con tarjetas del tipo Compact Flash (CF) o Secure Digital (SD). Dependiendo de modelos también pueden realizar conexiones inalámbricas a puntos Wi-Fi (Wireless Fidelity) o con otros dispositivos mediante puerto de infrarrojos o Bluetooth. Los últimos modelos disponen de capacidad multimedia y permiten reproducir vídeo y sonido.

Los PDA fueron diseñados originalmente como dispositivos para gestionar la información personal, para ello contienen de serie un software básico que incluye una agenda o calendario, una lista para contactos o direcciones, una lista para notas y otra lista para tareas. Sin embargo, los PDA pueden aumentar su funcionalidad instalando software adicional que es una característica que los diferencia de las antiguas agendas electrónicas que existían con anterioridad (Al-Ubaydli, 2003) (Al-Ubaydli, 2006).

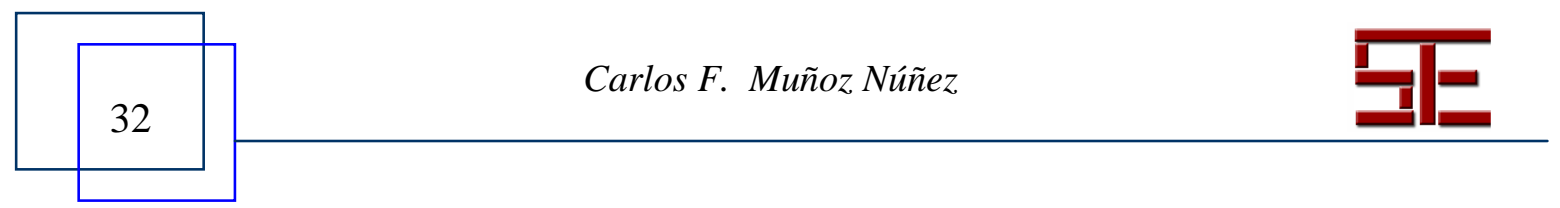




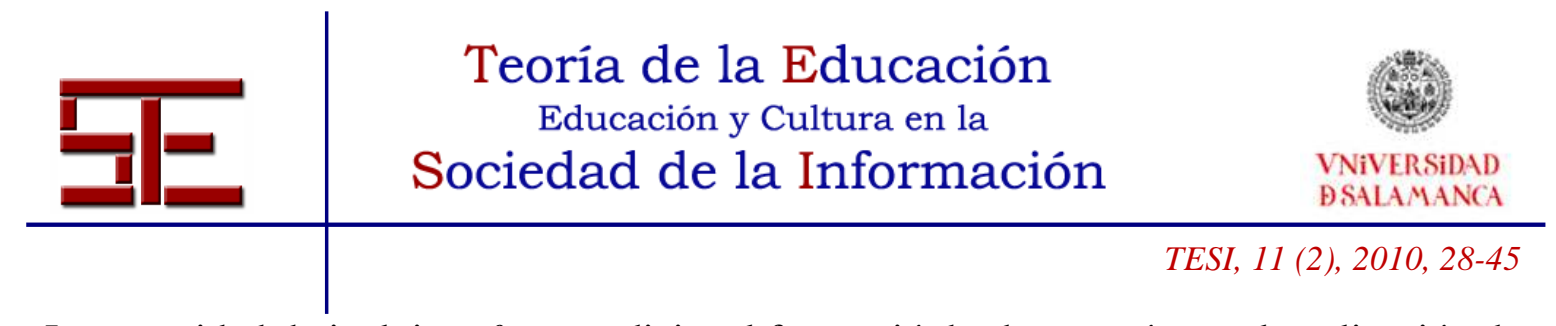

La capacidad de incluir software adicional favoreció desde sus orígenes la aplicación de PDA en la medicina clínica y en la educación médica (Honeybourne, Sutton, \& Ward, 2006) (Mcalearney, Schweikhart, \& Medow, 2004)(Nelson \& Library, 2005):

- como sistemas de ayuda a la toma de decisiones al permitir incluir farmacopeas, cálculo de dosis y control de interacciones medicamentosas, guías clínicas de buena práctica médica, referencias clínicas, etc.

- en tareas administrativas al permitir la prescripción electrónica, la organización de la agenda de citas y la codificación de procesos asistenciales.

- en la investigación al facilitar la recolección de datos in situ y la evaluación de estos datos, así como la lectura crítica.

- en la educación médica al permitir el registro de la actividad del estudiante, la realización de test en línea, la toma de apuntes, la visualización o preparación de presentaciones, la anotación de cualquier dato de interés, etc.

Desde su origen los PDA se consideraron dispositivos populares y valiosos en la medicina clínica, especialmente en la consulta de pacientes y en las salas de hospitalización y de urgencias, ya que pronto se vio que podían ser utilizados como sistemas portátiles de ayuda al diagnóstico a la cabecera del paciente, al ser capaces de almacenar información, organizar y registrar la actividad asistencial y acceder a fuentes de dato en línea. Podían sustituir a los manuales de bolsillo en papel y a los cuadernillos de notas de manera más eficaz, y su tamaño y peso eran lo suficientemente pequeños para caber en el bolsillo de una bata. Algunos llamaban a los PDA "peripheral brains" o cerebros periféricos. Otra función muy útil de los PDA era la posibilidad de que el usuario creara sus propios contenidos y así era posible transformar documentos en formatos estándar, incluidos en Microsoft ${ }^{\circledR}$ Word, lenguaje HTML o Adobe ${ }^{\circledR} p d f$, para ser visualizados posteriormente en un PDA.

Los PDA fueron muy populares desde la mitad de los años 90 hasta el final de la década del 2000. Aunque todavía siguen siendo unos instrumentos muy útiles y muy utilizados, se han dejado casi de fabricar y apenas quedan un par de modelos en el mercado, siendo sustituidos por los smartphones de los que se hablará más adelante.

Tanto los médicos ya formados como los médicos residentes han empleado y siguen empleando PDA. En general, parece existir una diferencia en el uso del PDA entre médicos especialistas y médicos en formación (residentes y fellows), los primeros utilizarían más la PDA para tareas administrativas y manejo de calendario y citas, mientras que los segundos la emplearían más para labores asistenciales (libros de referencia y calculadoras médicas) (McLeod, Ebbert, \& Lymp, 2003). Los médicos residentes han empleado el PDA para organizar historiales clínicos, llevar una lista de

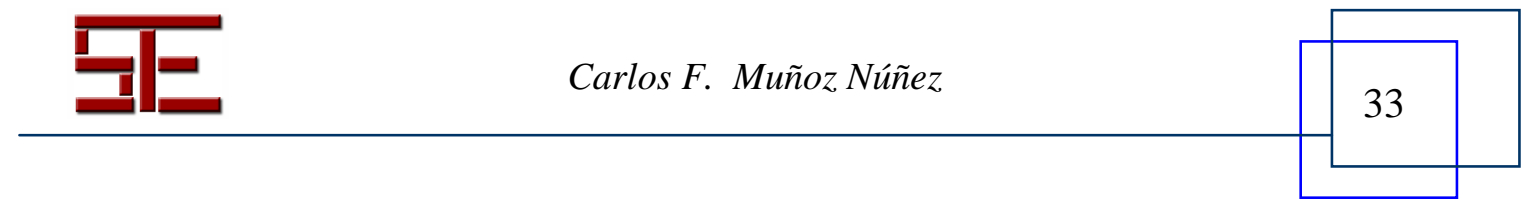




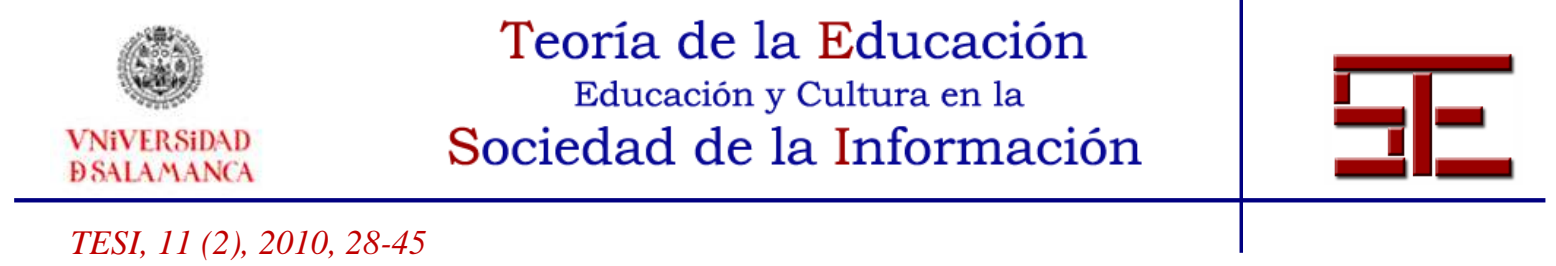

números de teléfono del centro hospitalario, enumerar listas de tareas, gestionar la asistencia a eventos y las consultas y realizar cálculos clínicos; el software que más emplean son las farmacopeas, los textos de referencia y las calculadoras clínicas (Jotkowitz et al., 2006). Los PDA también han sido utilizados como libro del residente (logbook) donde se registraba la actividad asistencial en diversas especialidades (radiología, ginecología, etc.) para realizar su evaluación.

Una característica muy útil en los PDA es el empleo de sistemas de alerta que adviertan al usuario de cualquier evento, como interacciones medicamentosas en el caso de un paciente, la disponibilidad de un análisis clínico o cualquier novedad bibliográfica o actualización de software (Johnson, Pancoast, Mitchell, \& Shyu, 2004).

En la educación de los estudiantes de Medicina los PDA se han utilizado tanto en el aula como durante las prácticas clínicas. En el aula se ha empleado la descarga previa de material docente en la PDA antes de una lección para su preparación; además se han utilizado para realizar evaluaciones interactivas con test de respuesta múltiple y para la docencia recibida (Kho, Henderson, Dressler, \& Kripalani, 2006).

Los estudiantes de Medicina también han utilizado los PDA para facilitar el registro y posterior evaluación de sus prácticas clínicas y conocer si se han alcanzado o no los objetivos docentes propuestos. El pequeño tamaño y el poco peso de los PDA facilita su fácil transporte en el bolsillo de una bata y su utilización durante la atención de los pacientes. El registro de datos en el mismo momento y lugar donde se produce la asistencia médica maximiza y optimiza el registro de datos. Estos datos se enviarán posteriormente a un registro central para su evaluación posterior. Una ventaja adicional que ofrecen los PDA es la posibilidad de incluir software adicional de referencia que puede servir al estudiante como sistema de ayuda al diagnóstico y facilitar el autoaprendizaje. Otro uso de los PDA en la educación médica es el registro de procedimientos médicos o quirúrgicos específicos que se consideran necesarios durante la formación y así determinar los puntos fuertes y débiles existentes. También pueden ser empleados para realizar exámenes de evaluación tipo test que se enviarían a un registro central para su posterior evaluación (Fischer, Stewart, Mehta, Wax, \& Lapinsky, 2003) (Axelson, Wårdh, Strender, \& Nilsson, 2007) (Kho, Henderson, Dressler, \& Kripalani, 2006) . Los PDA también han sido utilizados para favorecer la aplicación de los principios de la medicina basada en la evidencia durante las prácticas de los estudiantes de medicina utilizando software de ayuda a la toma de decisiones (Johnston et al., 2004).

Tanto los estudiantes de medicina, como los médicos en formación y los médicos especialistas coinciden en que se conseguiría un mejor y correcto uso de los PDA en la

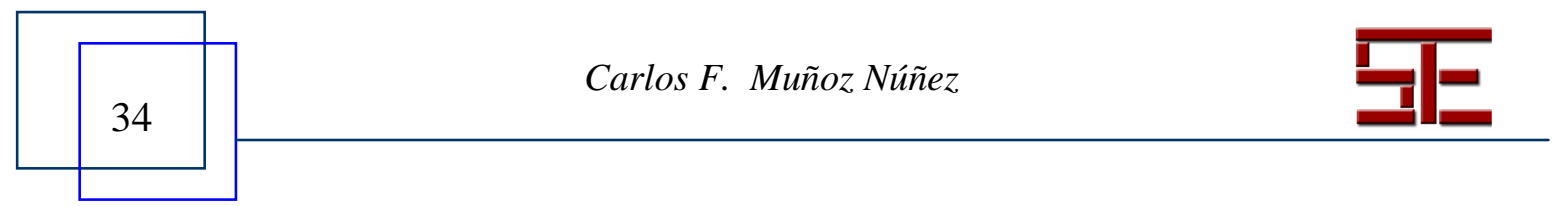




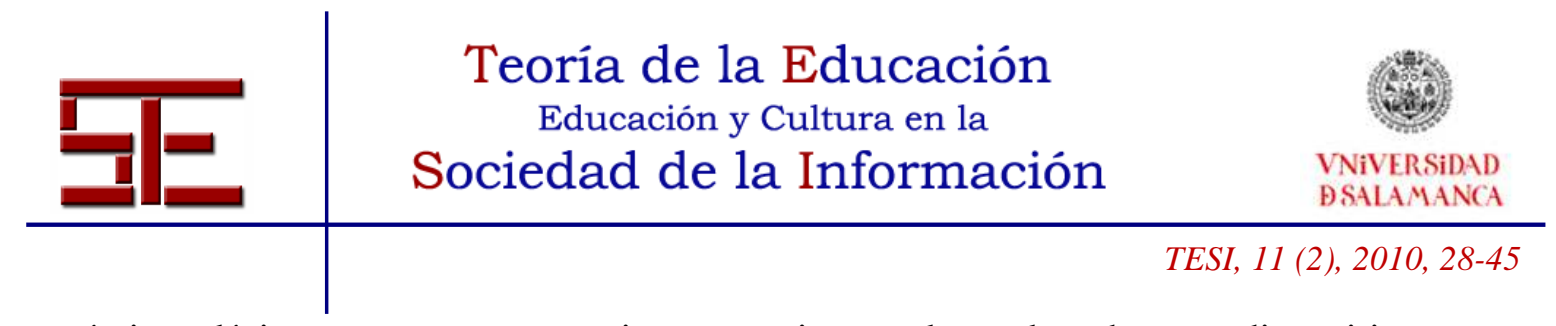

práctica clínica con un entrenamiento previo en el empleo de este dispositivo y no confiar en los conocimientos previos de informática de esos usuarios (De Groote \& Doranski, 2004) (Guerrieri \& Kokinova, 2009).

Entre las ventajas que ofrecen los PDA se pueden encontrar que facilita la movilidad, el acceso en tiempo real a la información, una mayor seguridad y reducción de errores médicos, la personalización del PDA para cada usuario, el soporte a la medicina basada en la evidencia, una mayor productividad y un aumento de la calidad asistencial ( $\mathrm{Lu}$, Xiao, Sears, \& Jacko, 2005).

Entre las desventajas que ofrecen los PDA se pueden encontrar factores físicos personales que impidan su manejo, menos efectivo que el registro en papel según algunos usuarios, no integración con la historia clínica electrónica, entrada de datos engorrosa, pantalla pequeña, fragilidad del dispositivo, dudas sobre la seguridad de los datos clínicos y percepción negativa por parte de los pacientes (Lu, Xiao, Sears, \& Jacko, 2005).

\section{2.- REPRODUCTORES MULTIMEDIA DIGITALES PORTÁTILES Y PODCASTING}

Un reproductor multimedia digital portátil es un dispositivo electrónico capaz de almacenar, organizar y reproducir archivos digitales que contengan exclusivamente audio o una combinación de audio e imágenes, en forma de vídeo, animaciones o imágenes fijas.

Los archivos digitales son habitualmente transferidos al dispositivo desde un ordenador personal vía cable USB (Universal Serial Bus o Bus Universal de serie) donde son almacenados en una memoria interna que puede ser un disco duro o una memoria flash. Algunos modelos permiten ampliar su capacidad de memoria mediante tarjetas de memoria flash que normalmente se inserta en una pequeña ranura de la carcasa del reproductor y que actuarían como memoria externa; otros modelos no permiten la ampliación de su memoria.

Aunque estos dispositivos están principalmente pensados para la reproducción de archivos multimedia, también pueden ser empleados como disco duro externo para almacenar y transportar archivos de todo tipo. Algunos modelos permiten la grabación de voz, capacidad que puede ser de utilidad para el registro directo de audio (por ejemplo de clases o conferencias).

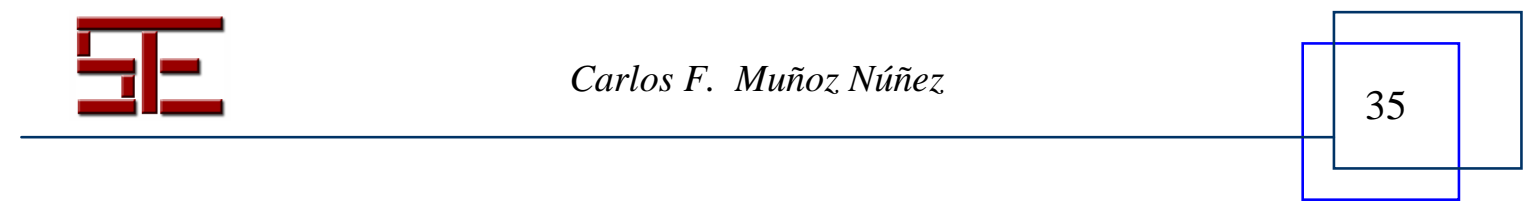




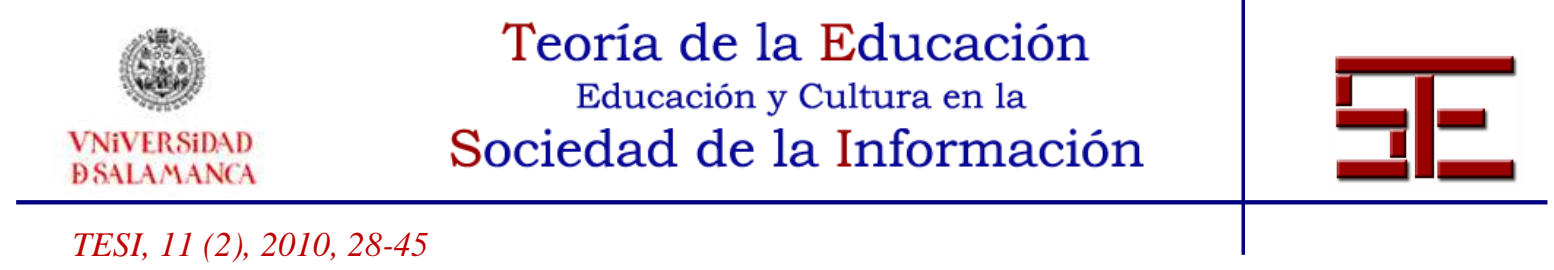

Estos dispositivos pueden reproducir diversos formatos de archivos digitales en función del fabricante. En general todos estos aparatos son capaces de reproducir archivos en formato MP3 (Moving Picture Experts Group [MPEG], capa de audio 3) y muchos de los que pueden reproducir vídeo reproducen archivos en formato MP4 (Moving Picture Experts Group [MPEG], capa de audio 4). El formato de archivos de audio MP3 es el formato de archivo de los podcasts de audio (Rowell, Corl, Johnson, \& Fishman, 2006a), mientras que el formato de archivos de video MP4 es el formato de archivo de los podcasts de video o vodcasts (Corl, Johnson, Rowell, \& Fishman, 2008).

Un podcast es un archivo multimedia que podemos descargar de Internet para reproducir posteriormente en nuestro ordenador personal o en un reproductor multimedia digital portátil. Fue elegida en 2005 palabra del año por el New Oxford American Dictionary y eso es una muestra de la relevancia que ha alcanzado ya esta tecnología. El término inglés podcast proviene de la combinación de dos palabras iPod ${ }^{\circledR}$ de Apple Inc. y broadcast, la primera corresponde al nombre del primer reproductor multimedia digital portátil de éxito (figura 2), mientras que la segunda es un término inglés que significa producción y emisión de programas de radio y televisión.

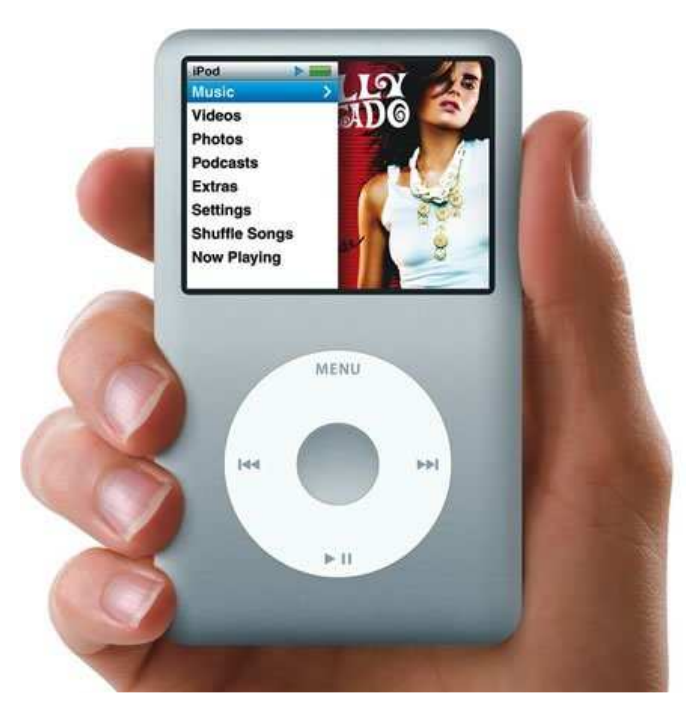

Figura 2: Reproductor multimedia digital portátil

El podcasting es el proceso por el que un autor genera un podcast y sigue los siguientes pasos (Rowell, Corl, Johnson, \& Fishman, 2006):

1. Grabación del contenido de audio en un archivo MP3.

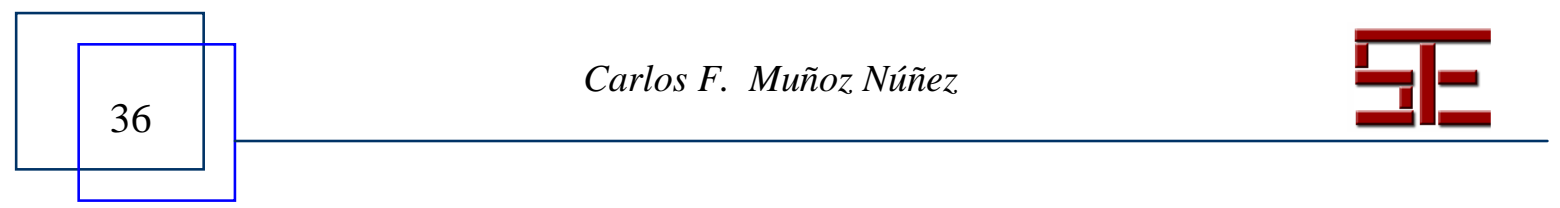




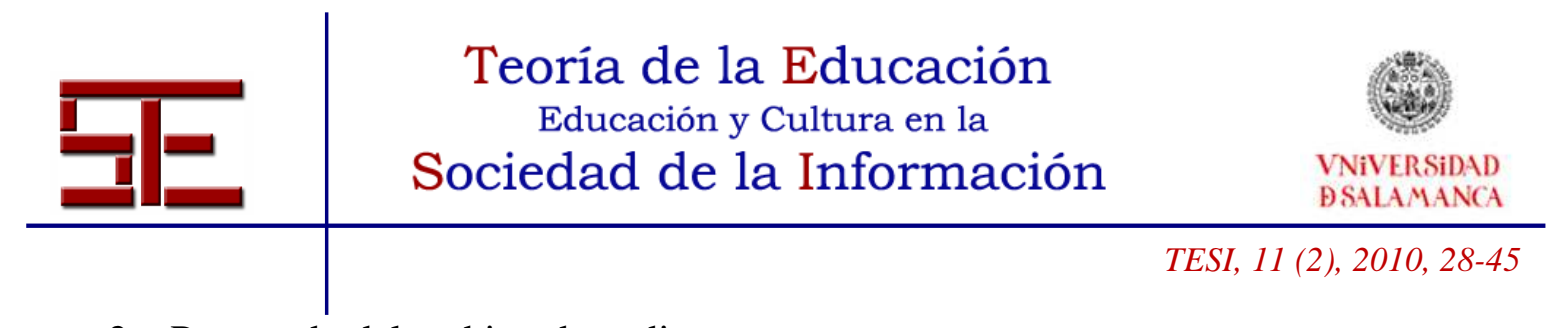

2. Procesado del archivo de audio.

3. Envío del contenido a un servidor de Internet para hacer disponible su contenido al público.

Aunque el término podcast originalmente se aplica a las emisiones de audio y el término vodcast a las emisiones de vídeo con audio, suele englobarse a ambas emisiones bajo la denominación genérica de podcast. La generación de un podcast de video sigue unos pasos similares a los descritos para un podcast de audio (Corl, Johnson, Rowell, \& Fishman, 2008).

El proceso de descarga de estos archivos al ordenador personal se suele automatizar con un software especial denominado agregador de contenidos que suele ser gratuito. Probablemente el más conocido sea iTunes ${ }^{\circledR}$ de Apple Inc.. Tras su descarga, el podcast queda almacenado en el ordenador personal hasta que ser transferido al reproductor multimedia digital portátil para su reproducción posterior en el lugar y momento deseados.

Un dato a tener en cuenta es que para poder descargar un podcast, previamente hay que solicitar la suscripción al mismo que suele ser gratuita. Una vez realizada, cada vez que activemos el software agregador de contenidos éste buscará cualquier nueva actualización de contenidos en el sitio web que aloja al podcast y descargará automáticamente cualquier nuevo podcast que haya aparecido desde nuestra última visita. La suscripción a un podcast determinado se puede hacer desde la web que ofrece el podcast o directamente desde el agregador que empleemos. Desde iTunes es muy sencillo, tan sólo hay que acceder al iTunes Store, seleccionar podcasts y realizar la búsqueda del podcast que deseemos; una vez decidamos qué podcast es de nuestro interés realizamos la suscripción.

Aunque es una tecnología muy reciente su potencial es enorme, especialmente en el ámbito docente. Puede ser un gran complemento a la docencia presencial en el aula, ya que por ejemplo los contenidos de una determinada lección pueden estar disponibles en forma de podcast días antes de ser impartida en el aula y eso permite al alumno poder revisarla a su ritmo todas las veces que precise, dónde y cuándo decida, antes de acudir a clase.

Existen ya diversas experiencias como la descrita en el campo de la docencia de la Medicina. En un reciente artículo, autores de la Universidad de Vanderbilt en EE.UU. estudian el impacto en estudiantes de primer año de Medicina de un curso en podcast sobre "Bases moleculares de la Medicina", el resultado mostró una buena aceptación de esta tecnología por los estudiantes, ya que consideraban que les ayudaba a estudiar

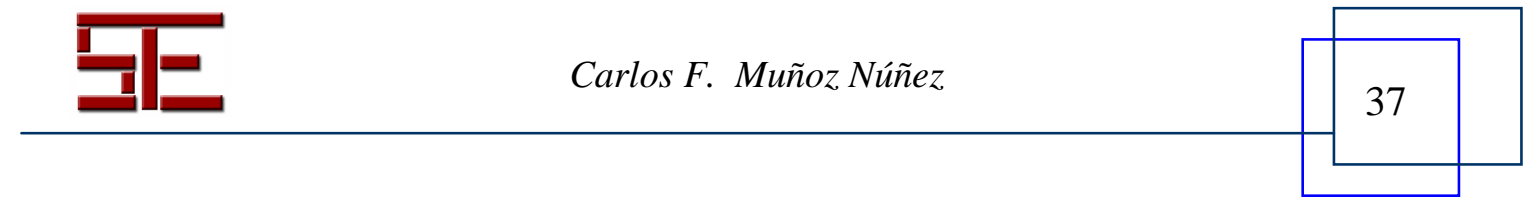




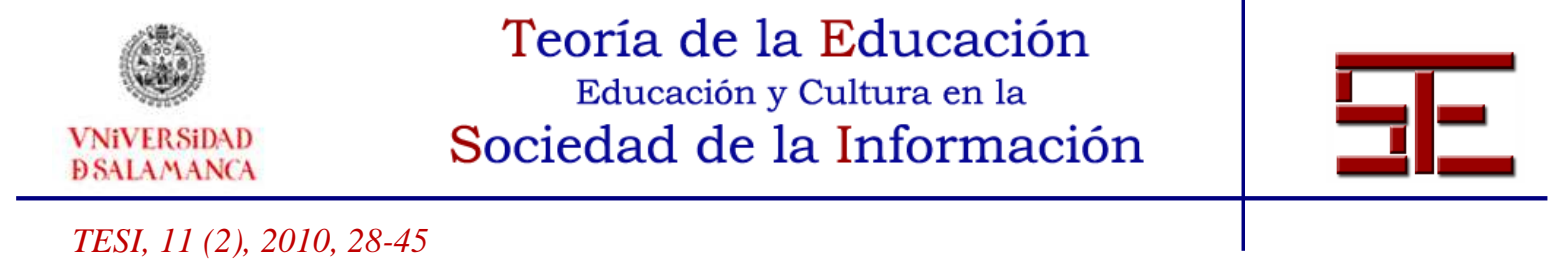

mejor la materia y reducía su estrés y ansiedad; los autores no observaron una menor asistencia a las clases presenciales (Pilarski, Alan Johnstone, Pettepher, \& Osheroff, 2008). También se han empleado por investigadores británicos para la enseñanza de la Cirugía General a estudiantes de Medicina con similar aceptación por los alumnos (Shantikumar, 2009).

La utilización de esta tecnología presenta el peligro potencial de la falta de asistencia del alumnado a las clases presenciales. Sin embargo, las experiencias descritas no apoyan esta suposición. En cualquier caso, los podcasts nunca deberían ser un sustituto de la interacción profesor-alumno, y su papel debería ser complementario favoreciendo que el estudiante revise conceptos y estudie a su ritmo fuera del aula.

Otra posible crítica a la tecnología podcast es que se trataría esencialmente de un modo de aprendizaje pasivo (Jham, Duraes, Strassler, \& Sensi, 2008), para evitar este problema puede ser efectiva la creación de podcasts interactivos en los que se pida al usuario que responda a una pregunta o se exija una interacción del usuario para proseguir; esto se puede realizar con una nueva tecnología conocida como podcast enriquecido (enhanced podcast en inglés) en el que se emplean audio e imágenes estáticas que contienen hipervínculos y marcadores (Thapa \& Richardson, 2010).

La Society of Critical Care Medicine de EE.UU. fue la primera sociedad científica médica norteamericana en crear un podcast que llamó "iCritical Care" (Savel, Goldstein, Perencevich, \& Angood, 2007). Diversas publicaciones biomédicas, entre ellas Nature, Lancet, New England Journal of Medicine y Journal of the American Medical Association ofrecen parte de sus contenidos en podcasts, generalmente los resúmenes y material suplementario (editoriales, entrevistas con autores de los artículos, etc.) (Clauson \& Vidal, 2008) (Wilson, Petticrew, \& Booth, 2009).

Además de para la reproducción de podcasts el reproductor multimedia iPod® de Apple, Inc. ha sido utilizado en la enseñanza de la anatomía (Trelease, 2006) y de la medicina clínica (Palmer \& Devitt, 2007). La última generación de reproductores multimedia de Apple, el iPod Touch® (figura 3) es también capaz de incorporar software nuevo para aumentar su funcionalidad.

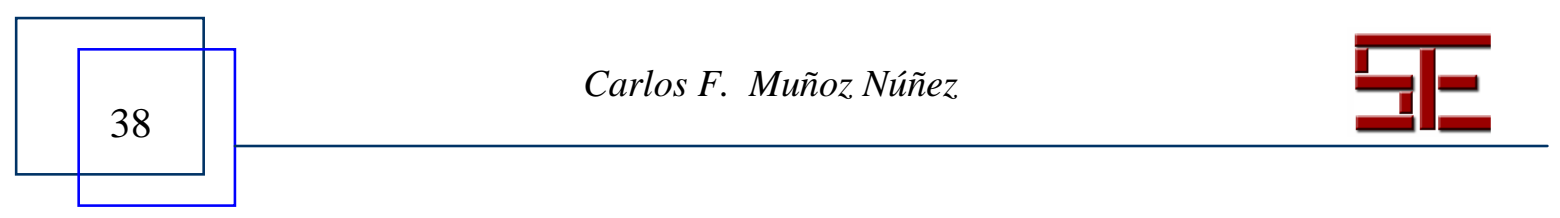




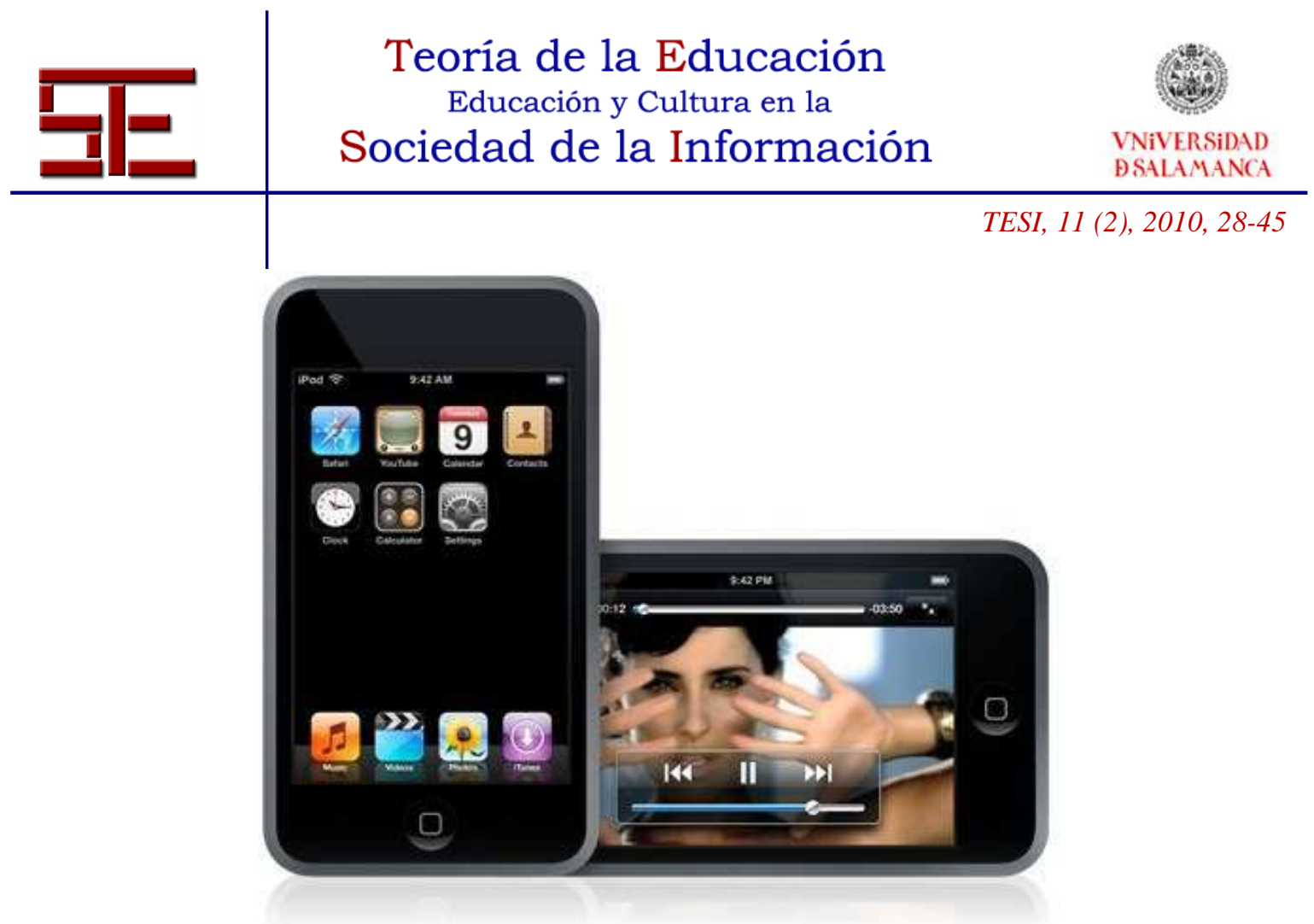

Figura 3; iPod Touch®

\section{3.- TELÉFONOS INTELIGENTES}

Los teléfonos inteligentes o smartphones son unos dispositivos móviles que se caracterizan por combinar en un mismo aparato las funciones propias de un teléfono móvil con las de un PDA, y en varios casos también son reproductores digitales multimedia.

Estos teléfonos debido a que tienen funciones de PDA pueden organizar la información personal y permiten la instalación de aplicaciones que aumenten sus prestaciones. También son capaces de intercambiar datos con un ordenador personal mediante un cable USB (Universal Serial Bus) o mediante tecnología inalámbrica Bluetooth, que también le permite interaccionar con otros dispositivos electrónicos, como por ejemplo un dispositivo manos libres. Los smartphones permiten el acceso a Internet a través de redes inalámbricas mediante tecnología Wi-Fi (Wireless Fidelity) y 3G (tercera generación de telefonía móvil), y en algunos casos pueden funcionar como módem para conectar un ordenador portátil a Internet a través de redes 3G.

Las características físicas de los teléfonos inteligentes varían según modelos, en general existen modelos con pantalla táctil y teclado virtual y modelos con un pequeño teclado físico y pantalla que puede ser táctil o no (con la que se interactuaría con un stylus, como las PDA).

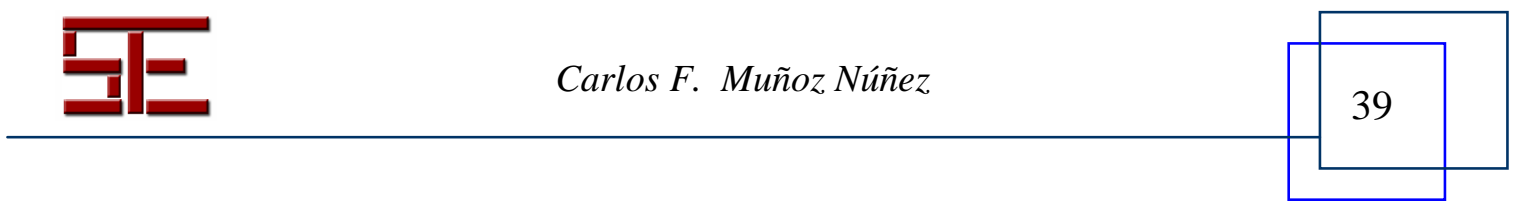




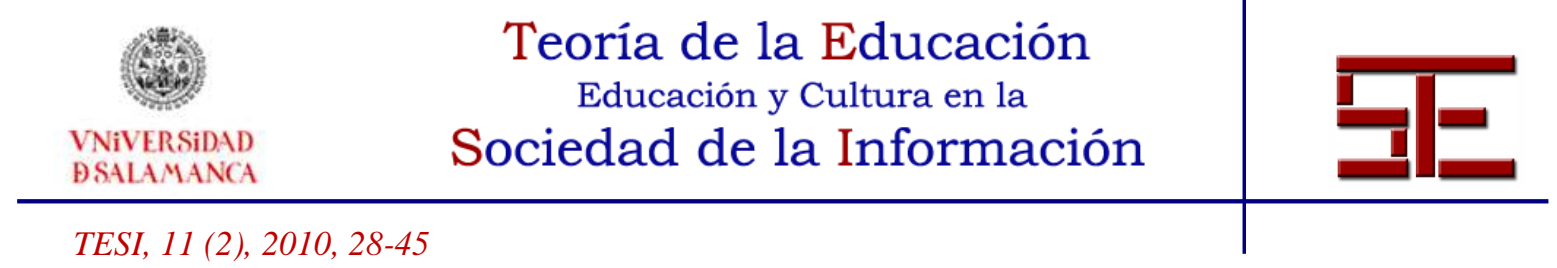

Al igual que con las PDA existen diversos sistemas operativos para smartphones. Así según el fabricante y según el modelo funcionará bajo un sistema operativo u otro. Los sistemas operativos que hay en la actualidad son Symbian, Blackberry, PalmOS, Pocket PC, Windows Mobile, Palm webOS, iPhone y Android (Burdette, Herchline, \& Oehler, 2008), y la elección de un sistema operativo u otros dependerá de para qué lo quiera utilizar el usurio.

Actualmente iPhone es el sistema operativo que dispone de más software para ampliar su funcionalidad, incluido el software de interés en medicina, debido a que fue el primer smartphone que fue un éxito y lleva más camino andado que otros. Actualmente existe una fuerte competencia entre los diversos sistemas operativos para ganar cuota de mercado, y recientemente se ha establecido una gran rivalidad entre los sistemas operativos iPhone (figura 4) y Android (figura 5), esta última dirigida por Google ${ }^{\circledR}$ y apoyada por la Open Handset Alliance que agrupa a 48 grandes compañías de telecomunicaciones, entre las que se encuentran entre otras Motorola ${ }^{\circledR}$, Intel ${ }$, Sony Ericsson ${ }^{\circledR}$ y Samsung® (Shih, Lakhani, \& Nagy, 2010).

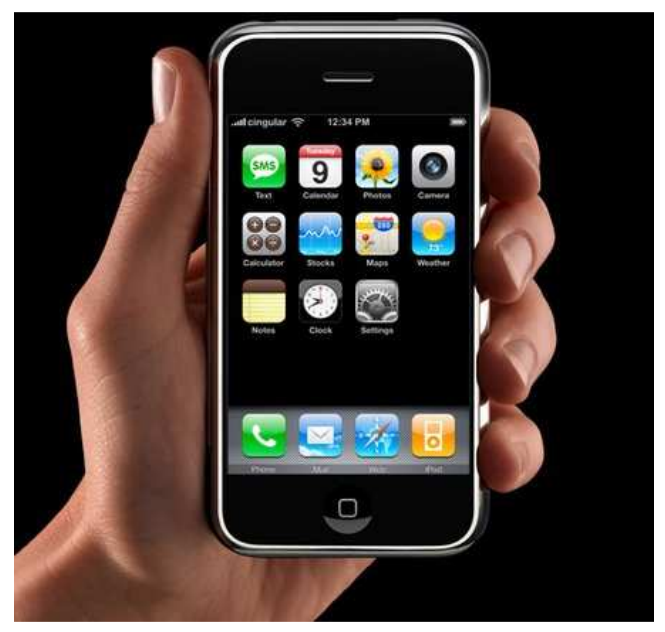

Figura 4; iPhone

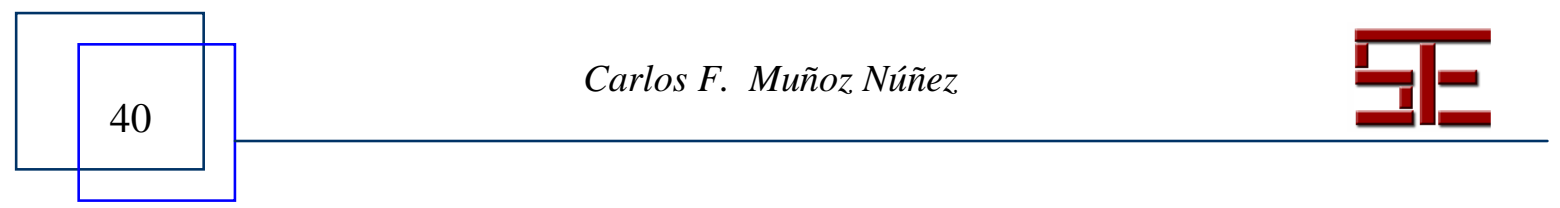



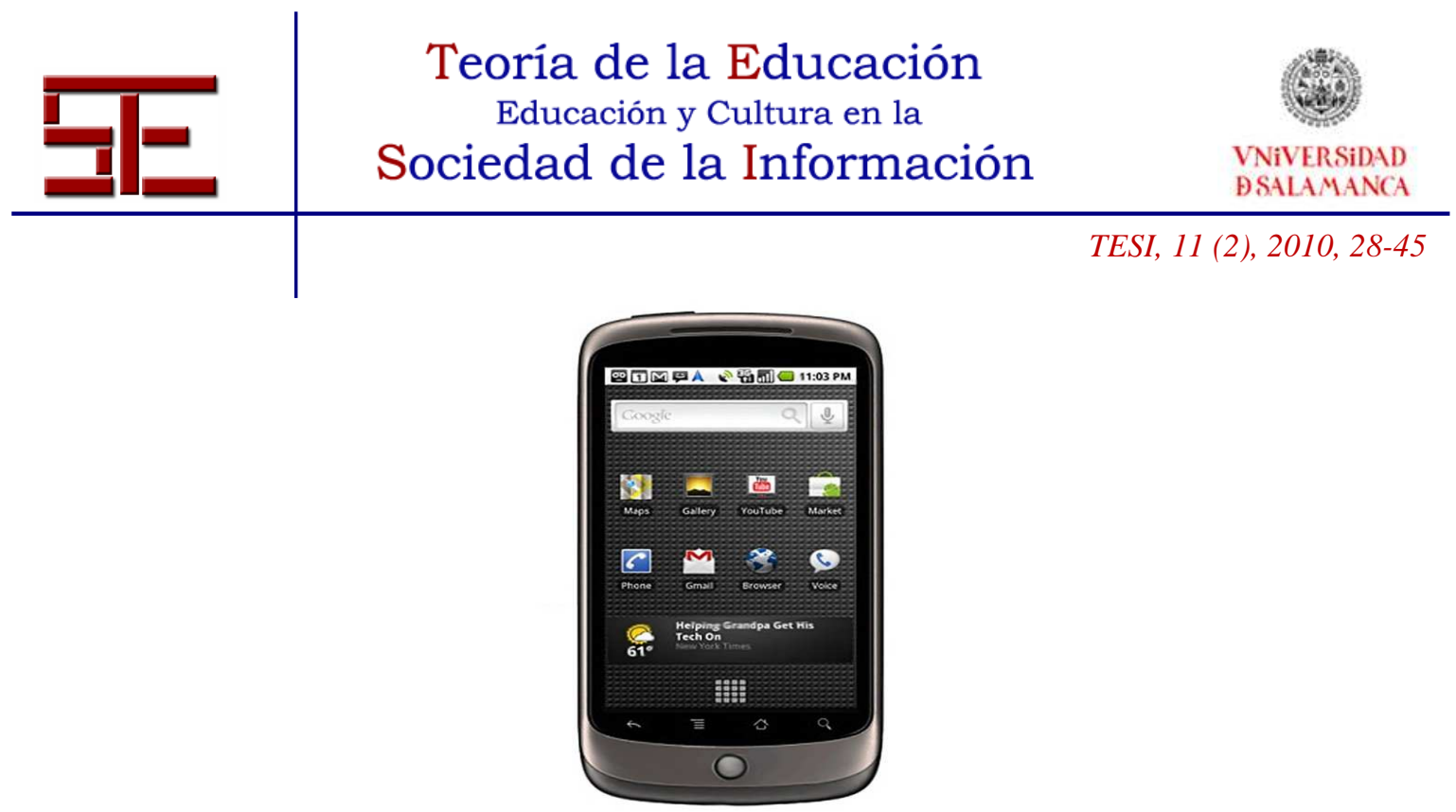

Figura 5; Android

Los smartphones han ido sustituyendo a los PDA en el mercado, por lo que no es extraño que muchas de las aplicaciones que vivieron su éxito en los PDA ya tengan su versión para smartphone, como por ejemplo el lector de documentos iSilo® o la suite ofimática DocumentsToGo® entre otras. Gran parte de lo que se ha comentado en el apartado de PDA es aplicable a los smartphones.

En los smartphones del tipo iPhone o Android es posible reproducir contenidos multimedia, por lo que son capaces también de almacenar y reproducir podcasts y funcionarían como los dispositivos comentados anteriormente.

Una de las características más valoradas de los smartphones por los médicos es la posibilidad de conexión inalámbrica a Internet a través de redes $3 \mathrm{G}$, lo que permite el acceso desde cualquier localización con cobertura telefónica y a cualquier hora de información médica actualizada que puede resultar especialmente valiosa en situaciones de urgencia (Burdette, Herchline, \& Oehler, 2008) (Focosi, 2008).

En el terreno educativo el iPhone ha sido también utilizado para distribuir contenidos docentes de anatomía (Trelease, 2008) que incluían flashcards, documentos pdf (portable document format), imágenes clínicas 3D, podcasts y procedimientos clínicos.

\section{4.- VENTAJAS E INCONVENIENTES DE LOS DISPOSITIVOS MÓVILES EN LA ENSEÑANZA MÉDICA}

Diversos trabajos han demostrado que los dispositivos móviles son útiles para la enseñanza médica:

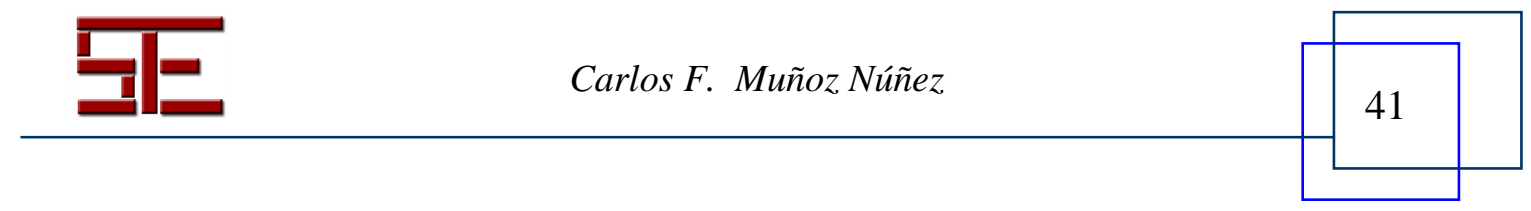




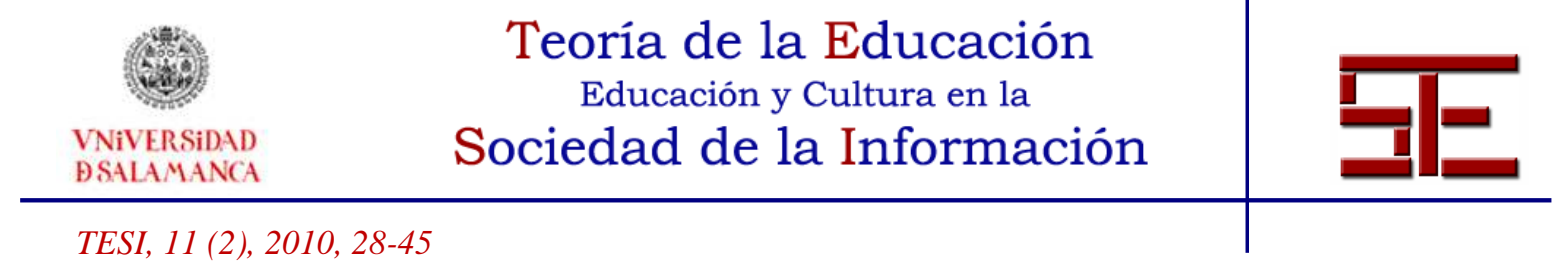

- Los PDA son útiles en diversos aspectos de la educación médica: durante las prácticas clínicas como sistemas de ayuda al diagnóstico, al permitir incorporar farmacopeas y otras bases de datos, calculadoras médicas y libros de texto de referencia entre otros, y para el registro de la actividad durante las prácticas al permitir determinar si se han alcanzado o no los objetivos de las mismas.

- Los dispositivos multimedia digitales portátiles permiten almacenar podcasts con clases magistrales que pueden revisarse una y otra vez cuándo y dónde se desee, audios para aprender auscultación cardiotorácica, vídeos de procedimientos clínicos que enseñen cómo se realiza una técnica o una intervención quirúrgica etc.

- Los nuevos modelos de smartphone son capaces de realizar las funciones de los dos dispositivos anteriores y añaden la función de teléfono móvil y sobre todo la posibilidad de acceso móvil a Internet, lo que permite entre otras cosas la consulta de bases de datos biomédicas online o el acceso a la historia clínica electrónica.

A pesar de estas indudables ventajas, el empleo de los dispositivos móviles en la educación médica presenta varios interrogantes que conviene resaltar:

- La mayoría de los trabajos sobre dispositivos móviles se han realizado en Estados Unidos y sería deseable una valoración más en profundidad y más internacional de estos dispositivos para valorar su eficacia en la educación.

- La gran mayoría de trabajos acerca de dispositivos móviles en la enseñanza médica se han realizado sobre PDA cuando actualmente casi han desaparecido del mercado desplazados por los smartphones y apenas quedan compañías que los fabriquen. Esto obliga a plantearse la pregunta de si vale la pena apostar por nuevas tecnologías educativas que pueden desaparecer por el interés económico de una compañía.

- Los smartphones son dispositivos caros y que para poder disponer de acceso a Internet hay que contratar una tarifa de transmisión de datos de pago.

- A pesar de tratarse de unos dispositivos fáciles de manejar, no hay que presuponer que los estudiantes de Medicina tienen habilidades informáticas especiales y habría que enseñarles cómo utilizarlos de la mejor manera posible (De Groote \& Doranski, 2004) (Guerrieri \& Kokinova, 2009).

- Aunque estos dispositivos móviles son populares y tienen un gran número de usuarios tampoco hay que presuponer que todos los estudiantes de Medicina los tienen. Esto es una limitación para la generalización de su empleo como herramientas educativas si no existe financiación por parte de las instituciones. Idéntico argumento se puede emplear para el acceso a Internet, no hay que presuponer que todos los estudiantes de Medicina lo tienen fuera del recinto

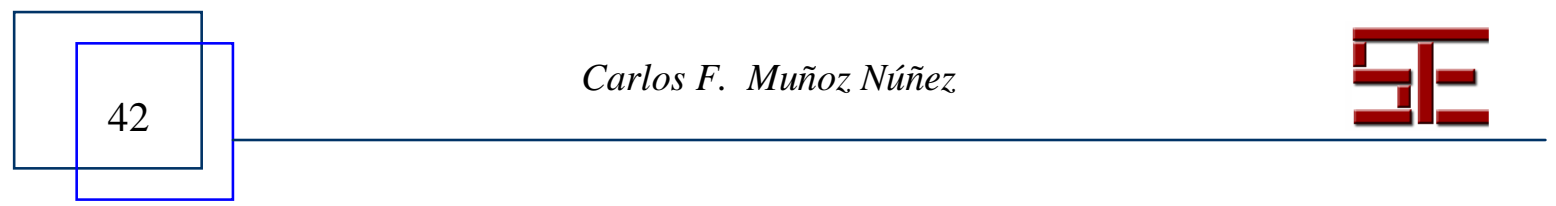




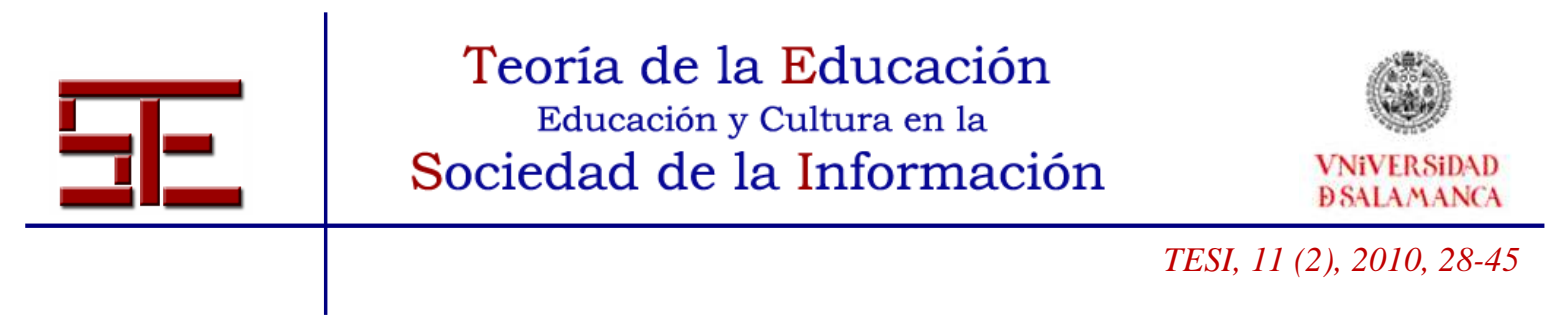

universitario (Kahn, Coppola, Rayne, \& Epstein, 2009) ' .

- No todos los estudiantes de Medicina están interesados en estas tecnologías, lo que dificultaría su introducción como herramienta docente.

- Estos dispositivos no deben competir con los ordenadores de sobremesa cuando estos sean más accesibles para realizar la misma función.

\section{5.- CONCLUSIONES Y PERSPECTIVAS DE FUTURO}

Los dispositivos móviles han demostrado ser útiles en la enseñanza médica. Los PDA han sido los dispositivos más estudiados en la literatura médica, aunque han ido desapareciendo del mercado y han sido sustituidos progresivamente por los smartphones. Aunque los smartphones pueden realizar las funciones de los PDA y añaden una mayor capacidad de reproducir archivos multimedia y la posibilidad de conexión a redes inalámbricas, actualmente son dispositivos caros y requieren el contrato de una tarifa de datos para emplear toda su capacidad. Hay un creciente interés por los podcasts como instrumento para difundir conocimiento y es probable que en los próximos años esta tecnología adquiera más relevancia en la educación médica.

\section{6.- BIBLIOGRAFÍA}

Al-Ubaydly, M. (2003). Handheld Computers for Doctors (1 ed.). Wiley.

Al-Ubaydly, M. (2006). The Doctor's PDA And Smartphone Handbook (1 ed.). Royal Society of Medicine Press.

Axelson, C., Wårdh, I., Strender, L.Y Nilsson, G. (2007). Using medical knowledge sources on handheld computers--a qualitative study among junior doctors. Medical Teacher, 29(6), 611-8.

Burdette, S. D., Herchline, T. E., Y Oehler, R. (2008). Surfing the web: practicing medicine in a technological age: using smartphones in clinical practice. Clinical Infectious Diseases, 47(1), 117-22.

Clauson, K. A., Y Vidal, D. M. (2008). Overview of biomedical journal podcasts. American Journal of Health-System Pharmacy : AJHP : Official Journal of the American Society of Health-System Pharmacists, 65(22), 2155-8.

Corl, F. M., Johnson, P. T., Rowell, M. R., Y Fishman, E. K. (2008). Internet-based dissemination of educational video presentations: a primer in video podcasting. AJR. American Journal of Roentgenology, 191(1), W23-7.

De Groote, S. L., Y Doranski, M. (2004). The use of personal digital assistants in the health sciences: results of a survey. Journal of the Medical Library Association : JMLA, 92(3), 341-8.

Fischer, S., Stewart, T. E., Mehta, S., Wax, R., Y Lapinsky, S. E. (2003). Handheld Computing in Medicine. Journal of the American Medical Informatics Association, 10(2), 139-149.

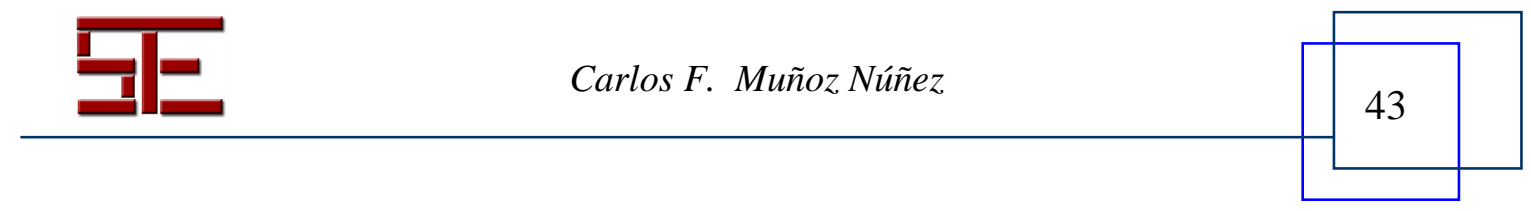




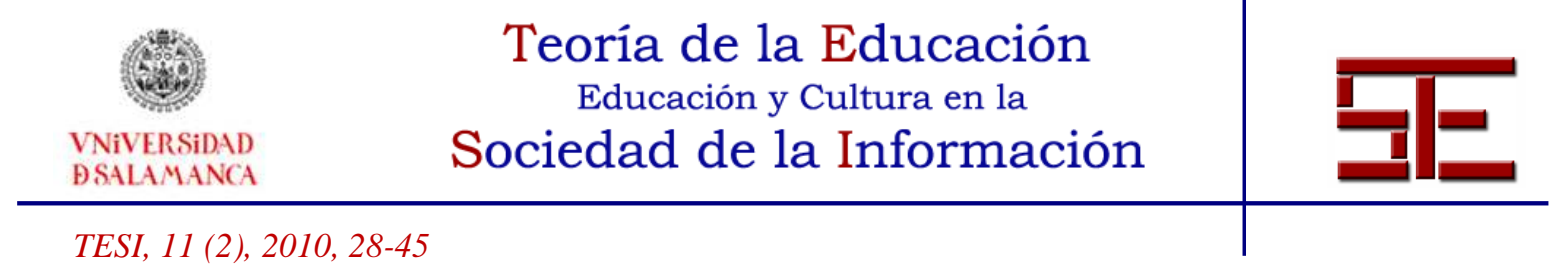

Focosi, D. (2008). Smartphone utilities for infectious diseases specialists. Clinical Infectious Diseases, 47(9), 1234-5.

Guerrieri, R., Y Kokinova, M. (2009). Does instruction in the use of personal digital assistants increase medical students' comfort and skill level? Medical Reference Services Quarterly, 28(1), 33-43.

Honeybourne, C., Sutton, S., Y Ward, L. (2006). Knowledge in the Palm of your hands: PDAs in the clinical setting. Health Information and Libraries Journal, 23(1), 51-9.

Jham, B. C., Duraes, G. V., Strassler, H. E., Y SENSI, L. G. (2008). Joining the podcast revolution. Journal of Dental Education, 72(3), 278-81.

Johnson, E. D., Pancoast, P. E., Mitchell, J. A., Y Shyu, C. (2004). Design and evaluation of a personal digital assistant- based alerting service for clinicians. Journal of the Medical Library Association : JMLA, 92(4), 438-44.

Johnston, J. M., Leung, G. M., Tin, K. Y., Ho, L., Lam, W., Fielding, R., Et Al. (2004). Evaluation of a handheld clinical decision support tool for evidence-based learning and practice in medical undergraduates. Medical Education, 38, 628-637.

Jotkowitz, A., Oh, J., Tu, C., Elkin, D., Pollack, L. A., Kerpen, H., Et Al. (2006). The use of personal digital assistants among medical residents. Medical teacher, 28(4), $382-4$.

Kahn, N., Coppola, W., Rayne, T., \& Epstein, O. (2009). Medical student access to multimedia devices: Most have it, some don't and what's next? Informatics for Health \& Social Care, 34(2), 100-105.

Kho, A., Henderson, L. E., Dressler, D. D., Y Kripalani, S. (2006). Use of handheld computers in medical education. A systematic review. Journal of General Internal Medicine, 21(5), 531-7.

Lu, Y., Xiao, Y., Sears, A., Y Jacko, J. A. (2005). A review and a framework of handheld computer adoption in healthcare. International Journal of Medical Informatics, 74(5), 409-22.

Mcleod, T. G., Ebbert, J. O., Y Lymp, J. F. (2003). Survey Assessment of Personal Digital Assistant Use among Trainees and Attending Physicians. Journal of the American Medical Informatics Association, 10(6), 605-607.

Mcalerarnye, A. S., Schweikhart, S. B., Y Medow, M. A. (2004). Doctors' experience with handheld computers in clinical practice: qualitative study, Br. Med. J., 328, 1162.

Nelson, D., y Library, P. M. (2005). More Than a Pocketful of Knowledge. Health Manag Technol, 26(2):30.

Palmer, E. J., Y Devitt, P. G. (2007). A method for creating interactive content for the iPod, and its potential use as a learning tool: Technical Advances. BMC Medical Education, 7(1), 32.

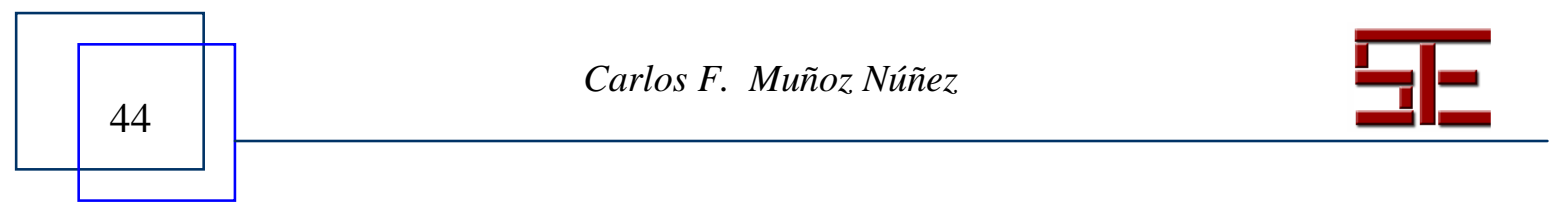




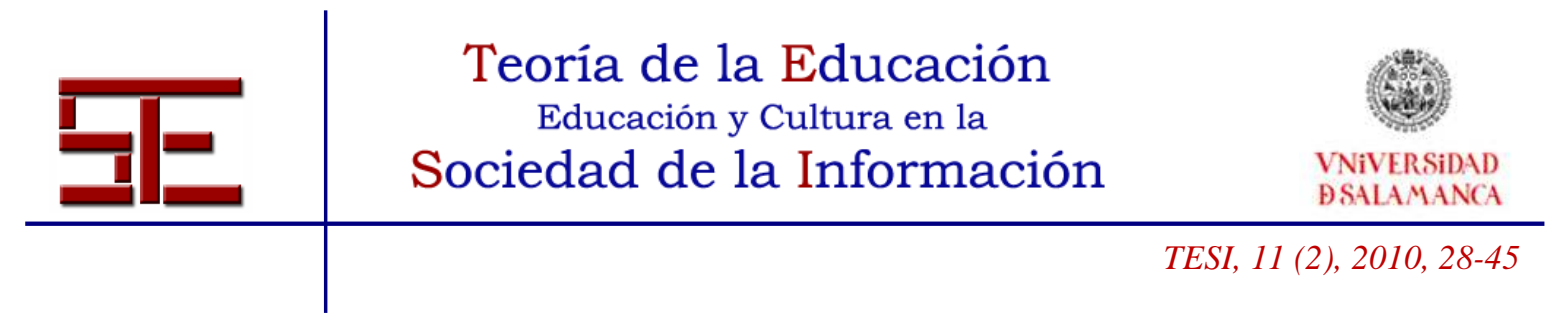

PilarskI, P. P., Alan Johnstone, D., Pettepher, C. C., Y Osheroff, N. (2008). From music to macromolecules: using rich media/podcast lecture recordings to enhance the preclinical educational experience. Medical Teacher, 30(6), 630-2.

Rowell, M. R., Corl, F. M., Johnson, P. T., Y Fishman, E. K. (2006). Internet-based dissemination of educational audiocasts: a primer in podcasting--how to do it. AJR. American Journal of Roentgenology, 186(6), 1792-6.

Savel, R. H., Goldstein, E. B., Perencevich, E. N., Y Angood, P. B. (2007). The iCritical care podcast: a novel medium for critical care communication and education. Journal of the American Medical Informatics Association : JAMIA, 14(1), 94-9.

Shantikumar, S. (2009). From lecture theatre to portable media: students' perceptions of an enhanced podcast for revision. Medical Teacher, 31(6), 535-538.

Shih, G., Lakhani, P., Y Nagy, P. (2010). Is android or iPhone the platform for innovation in imaging informatics. Journal of Digital Imaging : The Official Journal of The Society for Computer Applications in Radiology, 23(1), 2-7.

Thapa, M. M., Y Richardson, M. L. (2010). Dissemination of Radiological Information using Enhanced Podcasts. Academic Radiology, 17(3), 387-391.

Trelease, R. B. (2006). Diffusion of innovations: anatomical informatics and iPods. Anatomical Record. Part B, New Anatomist, 289(5), 160-8.

Trelease, R. B. (2008). Diffusion of innovations: smartphones and wireless anatomy learning resources. Anatomical Sciences Education, 1(6), 233-9.

Wilson, P., Petticrew, M., Y Booth, A. (2009). After the gold rush? A systematic and critical review of general medical podcasts. Journal of the Royal Society of Medicine, 102(2), 69-74.

Para citar el presente artículo puede utilizar la siguiente referencia:

Muñoz Nuñez, C.F. (2010). Dispositivos móviles en la educación médica, en Juanes Méndez, J.A. (Coord.) Avances tecnológicos digitales en metodologías de innovación docente en el campo de las Ciencias de la Salud en España. Revista Teoría de la Educación: Educación y Cultura en la Sociedad de la Información. Vol. 11, nº 2. Universidad de Salamanca, pp. 28-45 [Fecha de consulta: dd/mm/aaaa].

http://campus.usal.es/ revistas_trabajo/index.php/revistatesi/article/view/7070/7103

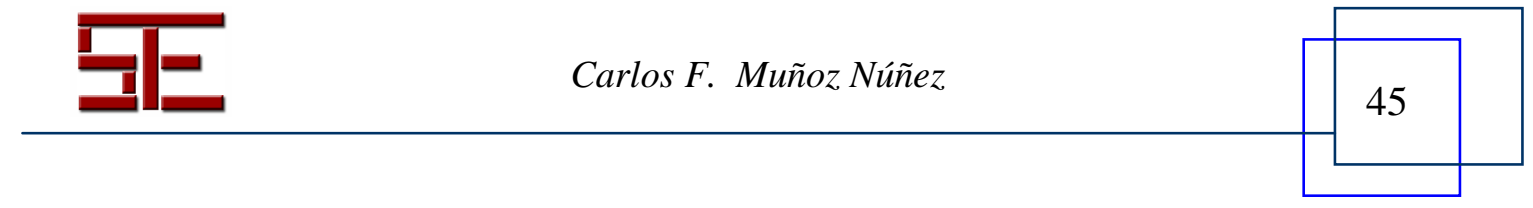

